\title{
Effect of genetic variation in the human S-adenosylhomocysteine hydrolase gene on total homocysteine concentrations and risk of recurrent venous thrombosis
}

\author{
Henkjan Gellekink ${ }^{1,2}$, Martin den Heijer ${ }^{2,3}$, Leo AJ Kluijtmans ${ }^{1}$ and Henk J Blom, \\ ${ }^{1}$ Laboratory of Pediatrics and Neurology, University Medical Center Nijmegen, The Netherlands; ${ }^{2}$ Department of \\ Endocrinology, University Medical Center Nijmegen, The Netherlands; ${ }^{3}$ Department of Epidemiology and Biostatistics, \\ University Medical Center Nijmegen, The Netherlands
}

Hyperhomocysteinemia is an independent and graded risk factor for arterial vascular disease and venous thrombosis. It is still debated via which mechanism homocysteine (Hcy) causes vascular disease. Sadenosylhomocysteine hydrolase (AHCY) catalyses the reversible hydrolysis of S-adenosylhomocysteine (AdoHcy) to Hcy. As an increase in AdoHcy, a strong inhibitor of many methyltransferases, is observed in hyperhomocysteinemic individuals, AdoHcy may play a role in the development of cardiovascular diseases by inhibiting transmethylation reactions. We sequenced the entire coding region and parts of the untranslated regions (UTRs) of the AHCY gene of 20 patients with recurrent venous thrombosis in order to identify genetic variation within this gene. We identified three sequence variants in the AHCY gene: a C $>$ T transition in the $5^{\prime}$ UTR $(-34$ bp $C>T)$, a missense mutation in exon 2 , which mandates an amino-acid conversion at codon 38 (112 C > T; Arg38Trp) and a silent mutation in exon 4 (390 C > T; Asp130Asp). We studied the effect of the first two variants on total plasma Hcy and venous thrombosis risk in a case-control study on recurrent venous thrombosis. The two polymorphisms under study seem to have no evident effect on tHcy. The adjusted relative risk of venous thrombosis associated with the 112CT genotype compared with $112 \mathrm{CC}$ individuals was $1.27(95 \% \mathrm{Cl} 0.55-2.94)$, whereas the $-34 \mathrm{CT}$ genotype confers a risk of $1.25(95 \% \mathrm{Cl} 0.44-3.52)$ compared with the wild-type genotype at this locus. However, the wide confidence intervals do not allow firm conclusions to be drawn.

European Journal of Human Genetics (2004) 12, 942-948. doi:10.1038/sj.ejhg.5201237

Published online 7 July 2004

Keywords: S-adenosylhomocysteine hydrolase; total homocysteine; recurrent venous thrombosis

\section{Introduction}

An elevated total plasma homocysteine (tHcy) concentration, also referred to as hyperhomocysteinemia, is an independent and graded risk factor for cardiovascular

*Correspondence: Dr HJ Blom, Laboratory of Pediatrics and Neurology (424), University Medical Center Nijmegen, PO Box 9101, 6500 HB Nijmegen, The Netherlands. Tel: + 3124 3613469; Fax: + 3124 3618900; E-mail: h.blom@cukz.umcn.nl

Received 21 January 2004; revised 25 March 2004; accepted 5 May 2004 disease, including venous thrombosis, peripheral, cerebral and coronary artery disease. ${ }^{1-6}$ Homocysteine (Hcy) is formed following $S$-adenosylmethionine (AdoMet)-dependent methylation reactions and subsequent hydrolysis of $S$-adenosyl-L-homocysteine (AdoHcy) by AdoHcy hydrolase (AHCY; EC 3.3.1.1). Removal of Hcy is essential as the equilibrium of the reaction catalysed by AHCY strongly favours the formation of AdoHcy. Under normal conditions, the turnover rate of Hcy is sufficient enough to favour the hydrolysis of AdoHcy. This is important as 
AdoHcy is a potent inhibitor of most methyltransferases thereby affecting DNA, RNA, protein and lipid methylation. ${ }^{7,8}$ For example, in vivo studies have demonstrated that an elevated tHcy is associated with increased plasma and intracellular AdoHcy levels, which correlates well with DNA hypomethylation in different tissues including lymphocytes, brain and liver. ${ }^{7,9-11}$ Therefore, it has been postulated that the increase in AdoHcy and associated inhibition of transmethylation may, in part, explain the increased risk of cardiovascular disease in hyperhomocysteinemic individuals.

The AHCY gene has been assigned to chromosome 20cen-q13.1 (Ensembl locus 20q11.22) and consists of 10 exons spanning about $23 \mathrm{~kb}$. Native human AHCY is a cytosolic protein composed of four identical subunits and requires $\mathrm{NAD}^{+}$as a cofactor. ${ }^{12}$ In the past, three electrophoretic isoforms of AHCY have been identified, ${ }^{13-15}$ but the molecular basis underlying these isoforms is still obscure. Coulter-Karis and Hershfield ${ }^{16}$ were the first to report a full-length cDNA of AHCY from a human placental cDNA library. They identified a transcript of $1299 \mathrm{bp}$ encoding a 432 amino-acid protein of approximately $48 \mathrm{kDa}$ and reported a $\mathrm{G}>\mathrm{A}$ transition at nucleotide 256 of this transcript. However, no AHCY sequence data or frequency data of this $256 \mathrm{G}>\mathrm{A}$ transition in a larger group of individuals is available yet.

Very recently, Baric and co-workers reported an AHCYdeficient patient with strongly reduced activity in liver (10\%) and fibroblasts (3\%) compared with controls. This 8month-old boy suffered from severe myopathy and slow psychomotor development but showed no signs of cardiovascular disease. In addition, an increased tHcy of $15.9 \mu \mathrm{mol} / \mathrm{l}$ (normal $<8.9 \mu \mathrm{mol} / \mathrm{l}$ ) was observed, while AdoMet and AdoHcy levels were increased $\sim 30$ - and $\sim 150$-fold, respectively. Surprisingly, this condition was accompanied by DNA hypermethylation in leucocytes. ${ }^{17}$

It is still debated via which mechanism Hcy induces arterial vascular diseases and venous thrombosis. Since AHCY is thought to play a pivotal role in the control of transmethylation reactions via regulation of intracellular Hcy and AdoHcy levels, we sequenced the AHCY gene of 20 patients with a history of venous thrombosis. We aimed to identify genetic variation in order to assess a possible effect on tHcy and disease risk in a group of recurrent venous thrombosis patients and population-based controls. We hypothesize that if a disturbed methylation increases the risk of venous thrombosis, functionally relevant polymorphisms within the AHCY gene may increase disease risk even without concomitant hyperhomocysteinemia.

\section{Material and methods}

Patients and controls used in the case-control study Patients were selected from the files of the anticoagulant clinic in Leyenburg Hospital in The Hague, ${ }^{5,18}$ and a population-based control group was recruited via a general practice in The Hague. ${ }^{5}$ Each study participant was subjected to a standardized methionine-loading test. This test included a basal Hcy measurement (after overnight fasting) and a second Hcy assessment $6 \mathrm{~h}$ after an oral methionine loading (100 mg L-methionine per $\mathrm{kg}$ body weight dissolved in $200 \mathrm{ml}$ orange juice). During these $6 \mathrm{~h}$, the subjects obtained a protein-restricted diet. For the current study, DNA of 173 recurrent venous thrombosis patients and 438 controls was available.

\section{Patient selection for sequence analysis of the AHCY gene}

We hypothesized that functional polymorphisms in the AHCY gene would decrease the conversion of methionine to Hcy, which could be visualized by a diminished increase in tHcy upon methionine loading; This so called delta $(\Delta)$ tHcy can be calculated by subtracting fasting tHcy from postmethionine load (PML) tHcy. A total of 10 recurrent venous thrombosis patients were selected for sequence analysis of the AHCY gene based on their capacity to convert methionine to Hcy after a methionine load ( $\Delta$ tHcy $15.1 \pm 4.3 \mu \mathrm{mol} / \mathrm{l}$; range $4-18 \mu \mathrm{mol} / \mathrm{l})$. Another 10 venous thrombosis patients were selected randomly ( $\Delta$ tHcy $29.7 \pm 10.0$; range $20-53 \mu \mathrm{mol} / \mathrm{l})$. The mean $\Delta$ tHcy in the entire case group was $33.1 \pm 14.0 \mu \mathrm{mol} / \mathrm{l}$ (range $4-98 \mu \mathrm{mol} / \mathrm{l}$ ).

\section{Biochemical parameters}

Blood samples were drawn from the antecubital vein for determination of tHcy and for DNA extraction. EDTA samples for Hcy measurement were placed on ice immediately and centrifuged at $3500 \mathrm{~g}$ for $5 \mathrm{~min}$ with minimal delay. The plasma was separated and stored at $-20^{\circ} \mathrm{C}$. tHcy concentrations were measured in our laboratory by an automated high-performance liquid chromatography method with reverse phase separation and fluorescent detection (Gilson 232-401 sample processor, Spectra Physics 8800 solvent delivery system and LC 304 fluorometer). The detection limit was less than $0.5 \mu \mathrm{mol} / 1$ with inter- and intrarun variation less than $6 \% .{ }^{19}$ A comparative study in which plasma tHcy was determined batch-wise in the laboratory of Pediatrics and Neurology of the University Medical Center Nijmegen (The Netherlands) and at the Department of Pharmacology at the University of Bergen (Norway) showed a systematic overestimation in tHcy concentration in the Nijmegen laboratory of $2.4 \mu \mathrm{mol} / \mathrm{l}$, but the ranking of the subjects was found not to be different between the two tests (precision 93\%). Therefore, it was decided to subtract $2.4 \mu \mathrm{mol} / 1$ from all tHcy measurements (fasting and PML) conducted in Nijmegen. ${ }^{19,20}$ DNA extraction was performed as described previously $^{21}$ and the DNA was stored at $4^{\circ} \mathrm{C}$. 
Sequence analysis of the AHCY gene

The molecular analysis of the AHCY gene was performed by genomic DNA sequencing of the entire coding region, including 75 nucleotides of the $5^{\prime}$ untranslated region (UTR) and the entire $3^{\prime}$ UTR. Intron-based primers were developed to avoid amplification of pseudogenes (GenBank accession number NT_028392.4) and to reveal potential splice site variants. PCR amplifications were performed in a total volume of $50 \mu \mathrm{l}$ on an iCycler (BioRad, the Netherlands); each mixture contained $50 \mathrm{ng}$ of both the forward and reverse primer (Biolegio BV, The Netherlands), $200 \mu \mathrm{M}$ dNTPs, $10 \mathrm{~mm}$ Tris-HCl buffer (pH 8.2), $50 \mathrm{~mm} \mathrm{KCl}, 1.0-2.0 \mathrm{mM} \mathrm{MgCl}_{2}$ (see Table 1), $0.5 \mathrm{U}$ of recombinant $\mathrm{Taq}$ polymerase, 5\% DMSO (all from Invitrogen, The Netherlands) and $75 \mathrm{ng}$ DNA. PCR conditions were as follows: initial denaturation of $4 \mathrm{~min}$ at $94^{\circ} \mathrm{C}, 35$ cycles of $94^{\circ} \mathrm{C} / 30 \mathrm{~s}$ (denaturation), $50-60^{\circ} \mathrm{C} / 30 \mathrm{~s}$ (annealing, see Table 1) and $72^{\circ} \mathrm{C} / 60 \mathrm{~s}$ (elongation), and a final extension of $7 \mathrm{~min}$ at $72^{\circ} \mathrm{C}$. The PCR products obtained were analysed on a $2 \%$ agarose gel and subsequently sequenced on an ABI Prism 377 automated sequencer using the ABI Prism Big Dye Terminator cycle sequence kit according to the instructions of the manufacturer ( $\mathrm{PE}$ Biosystems, The Netherlands). Sequence variants identified during the experiment (see Table 2) were screened for in our study populations using PCR-RFLP analyses.

\section{Mutation analysis of AHCY $112 \mathrm{C}>\mathrm{T}$ variant}

A C $>$ T transition in exon 2 at nucleotide position 112 (relative to the adenosine in the translation initiation codon; AHCY mRNA reference sequence NM_000678) of the AHCY gene was found. This transition abolishes a
BsrB1 restriction site, allowing RFLP analysis. PCR amplification, using primerset 2 (see Table 1), resulted in a fragment of $338 \mathrm{bp}$ and was digested by $5 \mathrm{U}$ of the restriction enzyme BsrB1 (New England Biolabs, Inc.) for $2 \mathrm{~h}$ at $37^{\circ} \mathrm{C}$, followed by gel electrophoresis analysis on a $2 \%$ agarose gel. Fragments of 159 and 179 bp identify the $112 \mathrm{C}$ allele, while the $112 \mathrm{~T}$ allele shows only one fragment of $338 \mathrm{bp}$. Genotype data was not available from one recurrent venous thrombosis patient $(n=172)$ and one control individual $(n=437)$.

\section{Mutation analysis of AHCY $-34 \mathrm{C}>\mathrm{T}$ variant}

We found a $\mathrm{C}$ to $\mathrm{T}$ transition (nucleotide -34 relative to the adenosine in the translation initiation codon; AHCY mRNA reference sequence NM_000678) in the 5' UTR of the AHCY gene. This transition creates an additional MnlI restriction site, allowing RFLP analysis. PCR amplification, using primerset 1 (see Table 1), resulted in a fragment of $195 \mathrm{bp}$, which was digested by $5 \mathrm{U}$ of the restriction enzyme Mnll, New England Biolabs, Inc., for $2 \mathrm{~h}$ at $37^{\circ} \mathrm{C}$, followed by gel electrophoresis analysis on a $4 \%$ agarose gel. Fragments of 148 and $47 \mathrm{bp}$ identify the $-34 \mathrm{C}$ allele, while the $-34 \mathrm{~T}$ allele shows fragments of 121,47 and $27 \mathrm{bp}$. The additional MnlI restriction site forms an internal control of the assay. Genotype data was not available from three recurrent venous thrombosis patients $(n=170)$ and 13 control individuals $(n=425)$.

\section{Statistics}

All the analyses were performed using SPSS software. tHcy concentrations were logarithmically transformed prior to all analyses, and are expressed as a geometric mean with a

Table 1 Primer sequences and PCR conditions used for amplification of the AHCY gene

\begin{tabular}{|c|c|c|c|c|c|}
\hline Fragment & Primer & Sequence $\left(5^{\prime} \rightarrow 3^{\prime}\right)$ & $\left(\mathrm{MgCl}_{2}\right)(m M)$ & $T_{a n n}\left({ }^{\circ} \mathrm{C}\right)$ & Product size $(b p)$ \\
\hline \multirow[t]{2}{*}{1} & $5^{\prime}$ UTR F & cgccacgcgcatatccctg & & & \\
\hline & $5^{\prime}$ UTR R & ccccogccacgaacaagc & 2.0 & 60 & 195 \\
\hline \multirow[t]{2}{*}{2} & Exon $2 \mathrm{~F}$ & gtgaccgcccctcttggttgg & & & \\
\hline & Exon $2 \mathrm{R}$ & ccaccctggcacagtcgtcttc & 1.5 & 51 & 338 \\
\hline \multirow[t]{2}{*}{3} & Exon $3 \mathrm{~F}$ & caccctttcccttccacacag & & & \\
\hline & Exon $3 \mathrm{R}$ & gctaggattttgtggcggtgac & 1.5 & 51 & 442 \\
\hline \multirow[t]{2}{*}{4} & Exon $4 \mathrm{~F}$ & gttgggaaggaggtagttttggc & & & \\
\hline & Exon $4 \mathrm{R}$ & gctgcttgaggtgatgggagtc & 1.5 & 51 & 350 \\
\hline \multirow[t]{2}{*}{5} & Exon $5 \mathrm{~F}$ & gctttagggggtaaagatgagg & & & \\
\hline & Exon $5 \mathrm{R}$ & gcctgtctataaccgcttttgcc & 1.0 & 55 & 330 \\
\hline \multirow[t]{2}{*}{6} & Exon $6 \mathrm{~F}$ & ggccttgcctgeccetattg & & & \\
\hline & Exon $6 \mathrm{R}$ & ctctggecccagtggctgac & 1.5 & 51 & 295 \\
\hline \multirow[t]{2}{*}{7} & Exon $7 / 8 \mathrm{~F}$ & ggcaagggttggttgtcagc & & & \\
\hline & Exon $7 / 8 \mathrm{R}$ & ccatctcctcagctctcctccc & 1.0 & 60 & 476 \\
\hline \multirow[t]{2}{*}{8} & Exon $9 \mathrm{~F}$ & ggcactgttggaggcagagag & & & \\
\hline & Exon $9 \mathrm{R}$ & ctctggcaagccctgtgtgg & 1.0 & 60 & 363 \\
\hline \multirow[t]{2}{*}{9} & Exon $10 \mathrm{~F}$ & cagacgcgtgtaggggtcc & & & \\
\hline & Exon $10 \mathrm{R}$ & gaggagaggtggggcctg & 1.5 & 60 & 254 \\
\hline \multirow[t]{2}{*}{10} & 3' UTR1 F & cctccagctgctgtccttgc & & & \\
\hline & $3^{\prime}$ UTR1 R & gggctgaagaaccactggacc & 1.5 & 59 & 383 \\
\hline \multirow[t]{2}{*}{11} & $3^{\prime}$ UTR2 F & ggacttatacctgtgtgcttgg & & & \\
\hline & $3^{\prime}$ UTR2 R & gcagagtaccccgtgaatgc & 1.0 & 59 & 513 \\
\hline
\end{tabular}

$\left(\mathrm{T}_{\mathrm{ann}}=\right.$ annealing temperature $)$. 
95\% confidence interval (CI). Differences in tHcy concentration were determined by linear regression analysis and expressed as changes relative to the wild type. Odds ratios and 95\% CIs were calculated to estimate the relative risk of venous thrombosis in individuals that carry the mutant allele using logistic regression analysis.

\section{Results}

AHCY sequence analysis

In order to identify genetic determinants of Hcy, we sequenced the AHCY gene of 20 recurrent venous thrombosis patients. Sequence analysis of all 10 exons, part of the $5^{\prime}$ UTR (from nucleotide -75 to the translation initiation codon) and the entire $3^{\prime}$ UTR (nucleotide +22353 to +23369 ) of the AHCY gene revealed three sequence variants (Figure 1). The first was located in the $5^{\prime}$ UTR $34 \mathrm{bp}$ upstream of the translation initiation codon $(-34 \mathrm{bp}$ $\mathrm{C}>\mathrm{T}$ ). In one patient, a $\mathrm{C}>\mathrm{T}$ transition was found in exon 2 of the AHCY gene at cDNA position $112(112 \mathrm{C}>\mathrm{T})$. This mutation mandates an amino-acid substitution of a basic arginine to a neutral tryptophan at codon 38 (R38W). Finally, a synonymous $\mathrm{C}>\mathrm{T}$ variant was detected in exon 4 (nucleotide position 390, amino acid D130D). The variants were present in three separate patients, all in a heterozygous state (Table 2 and Figure 1). Since the $-34 \mathrm{C}>\mathrm{T}$ variant may affect gene expression and the $112 \mathrm{C}>\mathrm{T}$ variant mandates an amino-acid change and potentially affects protein function, we screened our population of recurrent venous thrombosis patients and populationbased controls for these variants to assess their effects on tHcy levels and recurrent venous thrombosis risk. The synonymous $390 \mathrm{C}>\mathrm{T}$ variant was not studied in further detail, although an effect on mRNA stability or the splicing process cannot be ruled out.

Baseline characteristics of study populations

The control group consisted of 438 individuals (average age $50.7 \pm 13.3$ years) from which $41.1 \%$ was male $(n=180)$.
Mean fasting and postload tHcy were 10.4 (95\% CI 10.110.8) $\mu \mathrm{mol} / \mathrm{l}$ and 38.3 (95\% CI $37.2-39.5) \mu \mathrm{mol} / \mathrm{l}$, respectively. The case group consisted of 180 recurrent venous thrombosis patients (average age $61.5 \pm 14.2$ years) from which $50.9 \%$ was male $(n=88)$. Mean fasting and postload tHcy were 12.5 (95\% CI $11.8-13.3) \mu \mathrm{mol} / \mathrm{l}$ and 44.4 (95\% CI 42.3-46.6) $\mu \mathrm{mol} / 1$, respectively.

\section{Association of AHCY sequence variants and tHcy}

Fasting tHcy concentrations did not differ between the AHCY $112 \mathrm{C}>\mathrm{T}$ genotypes in recurrent venous thrombosis patients and controls (Table 3). However, in heterozygous subjects, tHcy concentrations seemed to be increased after a methionine load compared with 112CC individuals but only in the case group (Table 3 ). With respect to the -34 $\mathrm{C}>\mathrm{T}$ variant, no differences in tHcy (fasting or PML) were observed between the genotypes (Table 4).

\section{AHCY genotype analyses and associated RVT risk} In the control group, the distribution of the genotypes defined by the $112 \mathrm{C}>\mathrm{T}$ variant was in Hardy-Weinberg equilibrium $(P=0.19)$ with an $112 \mathrm{~T}$ allele frequency of $3.0 \%$ among recurrent venous thrombosis patients and $2.7 \%$ among the controls. The crude odds ratio as an estimation of the relative risk of recurrent venous thrombosis for the 112CT genotype compared with the 112CC genotype was 1.22 (95\% CI 0.56-2.65). Adjustment for age and gender did not change this risk estimate (Table 5).

The genotype distribution defined by the $-34 \mathrm{C}>\mathrm{T}$ transition in the control group was in Hardy-Weinberg

Table 2 Sequence variants of the AHCY gene identified in this study

\begin{tabular}{llll}
\hline $\begin{array}{l}\text { DNA } \\
\text { variants }\end{array}$ & Location & $\begin{array}{l}\text { Amino acid } \\
\text { (substitution) }\end{array}$ & $\begin{array}{l}\text { Screening } \\
\text { method }\end{array}$ \\
\hline$-34 \mathrm{C}>\mathrm{T}$ & $5^{\prime}$ UTR & Arg38Trp & RFLP; - BsrB1 \\
$112 \mathrm{C}>\mathrm{T}$ & $\begin{array}{l}\text { Exon 2 } \\
\text { RFLP; }+ \text { Mnll }\end{array}$ \\
\hline $90 \mathrm{C}>\mathrm{T}$ & Exon 4 & Asp130Asp & Not screened \\
\hline
\end{tabular}

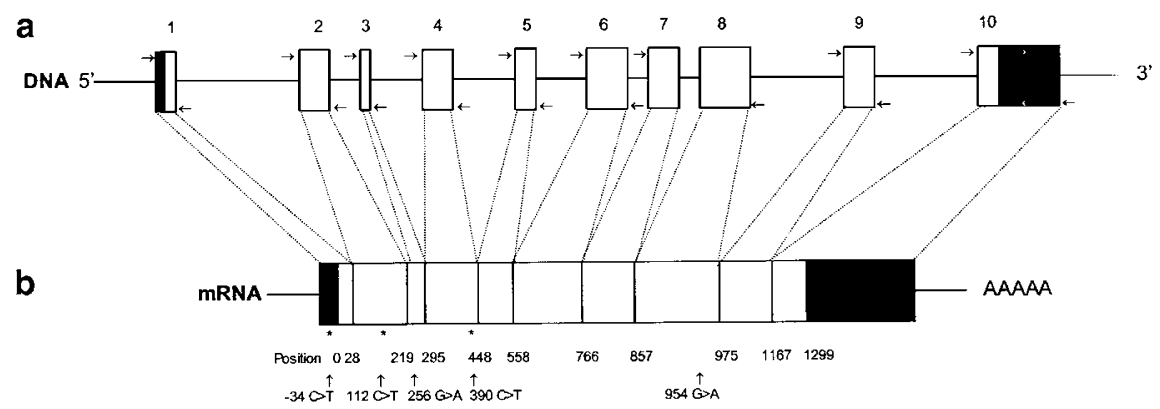

Figure 1 Schematic representation of the AHCY gene. (a) The coding regions are depicted as white boxes and the intronic regions as a horizontal line. The black boxes represent the untranslated regions. The arrows indicate the location of the (intronic) primers used for sequence analysis. (b) In this mRNA representation, sequence variants are indicated by vertical arrows (identified in this study denoted by *) with their cDNA position. 
Table 3 Association between AHCY genotypes defined by the $112 \mathrm{C}>\mathrm{T}$ variant and fasting and post-methionine load tHcy

\begin{tabular}{|c|c|c|c|c|c|}
\hline & $\begin{array}{l}\text { AHCY } \\
\text { genotype }\end{array}$ & $n$ & $\begin{array}{l}\text { Geometric mean tHcy } \\
(95 \% \mathrm{Cl})(\mu \mathrm{mol} / \mathrm{l})\end{array}$ & $\begin{array}{l}\text { Crude increase \% } \\
(95 \% \mathrm{Cl})\end{array}$ & $\begin{array}{c}\text { Adjusted increase \% } \\
(95 \% \mathrm{CI})^{a}\end{array}$ \\
\hline \multicolumn{6}{|l|}{ Fasting tHcy } \\
\hline Control & $\begin{array}{l}112 \mathrm{CC} \\
112 \mathrm{CT} \\
112 \mathrm{TT}\end{array}$ & $\begin{array}{r}415 \\
21 \\
1\end{array}$ & $\begin{array}{c}10.4(10.0-10.8) \\
11.3(9.5-13.3) \\
13.3\end{array}$ & $\begin{array}{c}0^{\mathrm{b}} \\
8.3(-9.0 \text { to } 28.0) \\
28.1\end{array}$ & $14.4(-2.1$ to 33.6$)$ \\
\hline Case & $\begin{array}{l}112 \mathrm{CC} \\
112 \mathrm{CT} \\
112 \mathrm{TT}\end{array}$ & $\begin{array}{r}162 \\
10 \\
0\end{array}$ & $\begin{array}{c}12.5(11.8-13.3) \\
12.5(9.8-16.0) \\
\simeq\end{array}$ & $0(-23.0$ to 29.0$)$ & $\begin{array}{c}0^{\mathrm{b}} \\
3.8(-16.6 \text { to } 29.3)\end{array}$ \\
\hline \multicolumn{6}{|l|}{$P M L t H c y$} \\
\hline Control & $\begin{array}{l}112 \mathrm{CC} \\
112 \mathrm{CT} \\
112 \mathrm{TT}\end{array}$ & $\begin{array}{r}415 \\
21 \\
1\end{array}$ & $\begin{array}{c}38.2(37.1-39.5) \\
39.3(34.2-45.1) \\
36.5\end{array}$ & $\begin{array}{c}0^{\mathrm{b}} \\
2.7(-11.0 \text { to } 18.0) \\
-4.5\end{array}$ & $\begin{array}{c}0^{\mathrm{b}} \\
6.1(-7.7 \text { to } 22.1) \\
-4.5\end{array}$ \\
\hline Case & $\begin{array}{l}112 \mathrm{CC} \\
112 \mathrm{CT} \\
112 \mathrm{TT}\end{array}$ & $\begin{array}{r}162 \\
10 \\
0\end{array}$ & $\begin{array}{c}43.8(41.7-46.1) \\
54.8(44.8-67.2) \\
-\end{array}$ & $25.1(1.5$ to 54.3$)$ & $27.7(3.9$ to 56.8$)$ \\
\hline
\end{tabular}

adjusted for age, gender and serum creatinine, ${ }^{b}$ reference category.

Table 4 Association between AHCY genotypes defined by the $-34 \mathrm{C}>\mathrm{T}$ variant and fasting and post-methionine load tHcy

\begin{tabular}{|c|c|c|c|c|c|}
\hline & $\begin{array}{l}\text { AHCY } \\
\text { genotype }\end{array}$ & $n$ & $\begin{array}{l}\text { Geometric mean tHcy } \\
(95 \% \mathrm{Cl})(\mu \mathrm{mol} / \mathrm{l})\end{array}$ & $\begin{array}{l}\text { Crude increase \% } \\
\quad(95 \% \mathrm{Cl})\end{array}$ & $\begin{array}{l}\text { Adjusted increase \% } \\
(95 \% \mathrm{Cl})^{a}\end{array}$ \\
\hline $\begin{array}{l}\text { Fasting } \mathrm{tHcy} \\
\text { Control }\end{array}$ & $\begin{array}{l}-34 \mathrm{CC} \\
-34 \mathrm{CT} \\
-34 \mathrm{TT}\end{array}$ & $\begin{array}{r}411 \\
14 \\
0\end{array}$ & $\begin{array}{c}10.4(10.1-10.8) \\
11.5(9.5-14.1) \\
\quad-\end{array}$ & $10.5(-9.9$ to 35.4$)$ & $11.1(-7.8$ to 33.7$)$ \\
\hline Case & $\begin{array}{l}-34 \mathrm{CC} \\
-34 \mathrm{CT} \\
-34 \mathrm{TT}\end{array}$ & $\begin{array}{r}164 \\
6 \\
0\end{array}$ & $\begin{array}{c}12.7(11.9-13.5) \\
11.0(8.0-16.0) \\
-\end{array}$ & $\begin{array}{c}0^{\mathrm{b}} \\
-12.9(-37.1 \text { to } 20.6)\end{array}$ & $-5.7(-29.0$ to 25.3$)$ \\
\hline $\begin{array}{l}\text { PML tHcy } \\
\text { Control }\end{array}$ & $\begin{array}{l}-34 \mathrm{CC} \\
-34 \mathrm{CT} \\
-34 \mathrm{TT}\end{array}$ & $\begin{array}{c}411 \\
14 \\
0\end{array}$ & $\begin{array}{c}38.3(37.1-39.5) \\
39.3(33.0-46.9) \\
-\end{array}$ & $2.8\left(\begin{array}{c}0^{\mathrm{b}} \\
-14.1\end{array}\right.$ to 22.9$)$ & $6.1(-7.7$ to 22.1$)$ \\
\hline Case & $\begin{array}{l}-34 \mathrm{CC} \\
-34 \mathrm{CT} \\
-34 \mathrm{TT}\end{array}$ & $\begin{array}{r}164 \\
6 \\
0\end{array}$ & $\begin{array}{l}44.4(42.3-46.6) \\
48.4(37.4-62.6) \\
-\end{array}$ & $9.0\left(-\frac{0^{b}}{-16.2}\right.$ to 41.7$)$ & $11.7(-13.6$ to 44.5$)$ \\
\hline
\end{tabular}

adjusted for age, gender and serum creatinine, ${ }^{b}$ reference category.

Table 5 Distribution of $112 \mathrm{C}>\mathrm{T}$ and $-34 \mathrm{C}>\mathrm{T}$ genotypes among recurrent venous thrombosis patients and populationbased controls and risk of venous thrombosis

\begin{tabular}{|c|c|c|c|c|}
\hline Genotype & RVT patients, $n(\%)(N=172)$ & Controls, $n(\%)(N=437)$ & Crude odds ratio $(95 \% \mathrm{Cl})$ & $\begin{array}{l}\text { Adjusted odds ratio }{ }^{a} \\
(95 \% \mathrm{CI})\end{array}$ \\
\hline $\begin{array}{l}112 \mathrm{CC} \\
112 \mathrm{CT} \\
112 \mathrm{TT}\end{array}$ & $\begin{array}{c}162(94.2) \\
10(5.8) \\
0\end{array}$ & $\begin{aligned} 415 & (95.0) \\
21 & (4.8) \\
1 & (0.2)\end{aligned}$ & $\begin{array}{c}1.0^{\mathrm{b}} \\
1.22(0.56-2.65) \\
-\end{array}$ & $\begin{array}{c}1.0^{\mathrm{b}} \\
1.27(0.55-2.94) \\
-\end{array}$ \\
\hline Genotype & RVT patients, $n(\%)(\mathrm{N}=170)$ & Controls, $n(\%)(N=425)$ & Crude odds ratio $(95 \% \mathrm{Cl})$ & Adjusted odds ratio ${ }^{\mathrm{a}}(95 \% \mathrm{Cl})$ \\
\hline $\begin{array}{l}-34 \mathrm{CC} \\
-34 \mathrm{CT} \\
-34 \mathrm{TT}\end{array}$ & $\begin{array}{c}164(96.5) \\
6(3.5) \\
0\end{array}$ & $\begin{array}{c}411(96.7) \\
14(3.3) \\
0\end{array}$ & $1.07(0.41-2.84)$ & $1.25(0.44-3.52)$ \\
\hline
\end{tabular}

adjusted for age and gender, ${ }^{b}$ reference category. 
equilibrium $(P=0.73)$. The frequency of the $-34 \mathrm{~T}$ allele was $1.8 \%$ among the recurrent venous thrombosis patients and $1.6 \%$ among the controls. The $-34 \mathrm{TT}$ genotype was too rare and therefore not observed. The relative risk of recurrent venous thrombosis due to the -34CT genotype compared with the wild type was 1.07 (95\% CI 0.41-2.84). After adjustment for age and gender, this odds ratio increased to 1.25 (95\% CI 0.44-3.52) (Table 5).

\section{Other sequence variants in AHCY coding region}

Coulter-Karis and Hershfield ${ }^{16}$ were the first to report a sequence of a full-length human placental cDNA of the AHCY gene. They reported a G to A transition in exon 3 at nucleotide 256, which results in an aspartic acid to asparagine conversion and abrogates a Sau96I restriction site. We screened 50 randomly selected controls for this polymorphism but did not detect this variant in the 100 alleles screened, nor did we find this mutation in 40 recurrent venous thrombosis patients (including the 20 patients used for the sequence analysis).

From these findings, we conclude that this transition may either represent a sequence artefact or is present only at frequency $<0.5 \%$. In addition, a synonymous mutation in exon 8 (954 G>A, K318 K) reported in the NCBI SNP Database was not found by sequencing analysis of the AHCY gene in the 20 recurrent venous thrombosis patients, and was not studied in further detail.

\section{Discussion}

It is still debated via which mechanism hyperhomocysteinemia induces arterial vascular disease and venous thrombosis. In addition to the direct effects of Hcy, the parallel increase in AdoHcy observed in hyperhomocysteinemic individuals $^{9,22}$ and associated effects on adenosine ${ }^{23}$ and transmethylation ${ }^{7,8}$ have emerged as alternative mechanisms for hyperhomocysteinemia-related cardiovascular disease. Laukkanen et al found that local CpG methylation in the superoxide dismutase gene in rabbit atherosclerotic aortas was reduced, ${ }^{24}$ while others observed global DNA hypomethylation in atherosclerotic lesions and leucocytes of cardiovascular disease patients. ${ }^{11,25}$

This is the first report of a systematic sequence analysis of the human AHCY gene in a group of recurrent venous thrombosis patients. We found three sequence variants of which two, that is $112 \mathrm{C}>\mathrm{T}$ and $-34 \mathrm{C}>\mathrm{T}$, were studied in a group of recurrent venous thrombosis cases and population-based controls to assess their effect on tHcy and recurrent venous thrombosis risk.

No effect of both sequence variants on fasting tHcy was observed in our case and control group. A higher tHcy after a methionine-load was observed but only in 112CT cases. This is in contrast to our expectations but may be explained by a negative effect of the polymorphism on the synthesis of AdoHcy out of Hcy resulting in elevation of tHcy, especially after increased methionine intake (ie methionine-load). However, this effect was not observed in our control population making it questionable whether the effect on tHcy is due to the polymorphism or simply a chance finding (due to low number of individuals carrying the $\mathrm{T}$ allele). Expression studies are needed to study the impact of these polymorphisms at the protein level that may reveal if and how the reversible AHCY-catalysed reaction is affected. The effect of these polymorphisms on electrophoretic mobility may also be investigated since differently migrating isoforms have been described in the past. ${ }^{13-15}$ However, no tissue samples were available to assess whether a mobility shift of the AHCY enzyme was correlated with the polymorphisms.

Very recently, Baric et $a l^{17}$ reported an AHCY-deficient patient with only a slightly elevated tHcy $(15.9 \mu \mathrm{mol} / \mathrm{l})$, while AdoHcy levels were increased $~ 150$-fold. This case shows that inhibition of AHCY, and associated changes in AdoHcy, does not necessarily lead to a dramatic change in tHcy. It would be interesting to measure AdoMet and AdoHcy levels, the ratio of which is an important predictor of cellular methylation capacity, to test the hypothesis that the polymorphisms described in this study affect AdoHcy and AdoMet levels. Unfortunately, AdoMet is very unstable in untreated blood samples and is partly degraded into AdoHcy (HJ Blom et al, unpublished results) making it impossible to measure these metabolites in the stored plasma samples of our study populations. This also prompted us to use thcy levels as a selection criterion although AdoHcy would have been a better candidate.

We assessed the relative risk conferred by these variants on developing two or more venous thrombosis events. The odds ratio for recurrent venous thrombosis was 1.22 (95\% CI 0.56-2.65) for the 112 CT genotype compared with the 112CC genotype. Similar results were obtained for the -34 bp C > T variant; an odds ratio of 1.07 (95\% CI $0.41-$ 2.84 was observed for the $-34 \mathrm{CT}$ genotype, which increased to 1.25 (95\% CI $0.44-3.52)$ after adjustment for age and gender. Although these risk estimates are in the range of venous thrombosis risk associated with the MTHFR 677 TT genotype, ${ }^{26}$ the low frequency of the polymorphisms described above underpowers this study to draw firm conclusions on disease risk conferred by these variants.

In conclusion, the AHCY gene harbours only little variation in our Dutch population of recurrent venous thrombosis patients. This underlines the importance of AHCY in methionine metabolism. The detected polymorphisms seem to have no important effect on tHcy, but an effect on AdoHcy and recurrent venous thrombosis risk cannot be ruled out and needs additional studies in larger populations. These studies, in which AdoMet and AdoHcy concentrations are measured as well, may contribute to our understanding via which mechanism a disturbed Hcy metabolism is associated with cardiovascular disease. 


\section{Acknowledgements}

This study was in part supported by Grant 2002B68 from the Netherlands Heart Foundation. Martin den Heijer, MD, PhD, is supported by a VENI grant from the Dutch Organization for Scientific Research (NWO). Leo AJ Kluijtmans, PhD, is a post-doctoral fellow of the Netherlands Heart Foundation (1999T023). Henk J Blom, PhD, is an established investigator of the Netherlands Heart Foundation (D97.021).

\section{References}

1 Andreassi MG, Botto N, Cocci F et al: Methylenetetrahydrofolate reductase gene C677T polymorphism, homocysteine, vitamin $\mathrm{B} 12$, and DNA damage in coronary artery disease. Hum Genet 2003; 112: 171-177.

2 The Homocysteine Studies Collaboration: Homocysteine and risk of ischemic heart disease and stroke: a meta-analysis. JAMA 2002; 288: 2015-2022.

3 Eichinger S, Stumpflen A, Hirschl M et al: Hyperhomocysteinemia is a risk factor of recurrent venous thromboembolism. Thromb Haemost 1998; 80: 566-569.

4 Refsum H, Ueland PM, Nygard O, Vollset SE: Homocysteine and cardiovascular disease. Annu Rev Med 1998; 49: 31-62.

5 den Heijer M, Blom HJ, Gerrits WB et al: Is hyperhomocysteinaemia a risk factor for recurrent venous thrombosis? Lancet 1995; 345: 882-885.

6 Clarke R, Daly L, Robinson K et al: Hyperhomocysteinemia: an independent risk factor for vascular disease. $N$ Engl J Med 1991; 324: $1149-1155$

7 James SJ, Melnyk S, Pogribna M, Pogribny IP, Caudill MA: Elevation in $S$-adenosylhomocysteine and DNA hypomethylation: potential epigenetic mechanism for homocysteine-related pathology. J Nutr 2002; 132 (8 Suppl): 2361S-2366S

8 Zhu BT: On the mechanism of homocysteine pathophysiology and pathogenesis: a unifying hypothesis. Histol Histopathol 2002; 17: $1283-1291$.

9 Yi P, Melnyk S, Pogribna M et al: Increase in plasma homocysteine associated with parallel increases in plasma $S$ adenosylhomocysteine and lymphocyte DNA hypomethylation. J Biol Chem 2000; 275: 29318-29323.

10 Zhu BT: Medical hypothesis: hyperhomocysteinemia is a risk factor for estrogen-induced hormonal cancer. Int J Oncol 2003; 22: $499-508$

11 Castro R, Rivera I, Struys EA et al: Increased homocysteine and $S$ adenosylhomocysteine concentrations and DNA hypomethylation in vascular disease. Clin Chem 2003; 49: $1292-1296$.

12 Hershfield MS, Aiyar VN, Premakumar R, Small WC: Sadenosylhomocysteine hydrolase from human placenta.
Affinity purification and characterization. Biochem $J$ 1985; 230: $43-52$.

13 Scozzari R, Sellitto D, Tassone F, Cerroni L, Aliquo MC: Family and population studies of SAHH and ADA polymorphisms. A possible pitfall in the ascertainment of SAHH electrophoretic phenotypes. Ann Hum Genet 1987; 51 (Part 4): 295-302.

14 Arredondo-Vega FX, Charlton JA, Edwards YH, Hopkinson DA, Whitehouse DB: Isozyme and DNA analysis of human $S$ adenosyl-L-homocysteine hydrolase (AHCY). Ann Hum Genet 1989; 53 (Part 2): 157-167.

15 Bissbort S, Bender K, Wienker TF, Grzeschik KH: Genetics of human $S$-adenosylhomocysteine hydrolase. A new polymorphism in man. Hum Genet 1983; 65: 68-71.

16 Coulter-Karis DE, Hershfield MS: Sequence of full length CDNA for human S-adenosylhomocysteine hydrolase. Ann Hum Genet 1989; 53 (Part 2): 169-175.

17 Baric I, Fumic K, Glenn B et al: S-adenosylhomocysteine hydrolase deficiency in a human: a genetic disorder of methionine metabolism. Proc Natl Acad Sci USA 2004; 101: $4234-4239$.

18 Keijzer MB, den Heijer M, Blom HJ et al: Interaction between hyperhomocysteinemia, mutated methylenetetrahydrofolatereductase (MTHFR) and inherited thrombophilic factors in recurrent venous thrombosis. Thromb Haemost 2002; 88: $723-728$.

19 te Poele-Pothoff MT, van den Berg M, Franken DG et al: Three different methods for the determination of total homocysteine in plasma. Ann Clin Biochem 1995; 32 (Part 2): 218-220.

20 De Bree A, Verschuren WM, Blom HJ et al: The homocysteine distribution: (Mis) judging the burden. J Clin Epidemiol 2001; 54: $462-469$.

21 Miller SA, Dykes DD, Polesky HF: A simple salting out procedure for extracting DNA from human nucleated cells. Nucleic Acids Res 1988; 16: 1215

22 Kerins DM, Koury MJ, Capdevila A, Rana S, Wagner C: Plasma $S$ adenosylhomocysteine is a more sensitive indicator of cardiovascular disease than plasma homocysteine. Am J Clin Nutr 2001; 74: 723-729.

23 Riksen NP, Rongen GA, Blom HJ et al: Potential role for adenosine in the pathogenesis of the vascular complications of hyperhomocysteinemia. Cardiovasc Res 2003; 59: 271-276.

24 Laukkanen MO, Mannermaa S, Hiltunen MO et al: Local hypomethylation in atherosclerosis found in rabbit Ec-Sod gene. Arterioscler Thromb Vasc Biol 1999; 19: 2171-2178.

25 Hiltunen MO, Turunen MP, Hakkinen TP et al: DNA hypomethylation and methyltransferase expression in atherosclerotic lesions. Vasc Med 2000; 7: 5-11.

26 Wald DS, Law M, Morris JK: Homocysteine and cardiovascular disease: evidence on causality from a meta-analysis. BMJ 2002; 325: 1202 . 